Gut, 1978, 19, 166-169

\title{
Measurement of bile acids in fasting gastric aspirates: an objective test for bile reflux after gastric surgery
}

\author{
A. M. HOARE 1 , M. R. B. KEIGHLEY, B. STARKEY, AND \\ J. ALEXANDER-WILliams²
}

From the Queen Elizabeth and General Hospitals, Birmingham

SUMMARY We measured the concentration of bile acids in gastric aspirates from patients who had had operations for peptic ulcer. Some patients were asymptomatic and some had postoperative symptoms of the type that have been attributed to duodenogastric reflux. Samples were obtained via a nasogastric tube when the patients were fasting, after food, after pentagastrin, and overnight. We related the concentration and amount of bile acid and the volume aspirated to the presence or absence of symptoms and compared the results with radiological and endoscopic assessments of duodenogastric reflux. The most useful index to discriminate between symptomatic and asymptomatic patients was the amount of bile reflux in half an hour's aspiration from the fasting stomach; this we have termed 'fasting bile reflux' (FBR) and expressed as $\mu$ mol bile acids refluxing/hour. A figure greater than $120 \mu \mathrm{mol} / \mathrm{h}$ was present in 17 of 22 symptomatic patients and in all who complained of bile regurgitation or bile vomiting. The FBR was less than $120 \mu \mathrm{mol} / \mathrm{h}$ in all of 20 asymptomatic patients, although some of them had reflux detected radiologically and endoscopically.

Bile vomiting has been reported as a complication of all types of operations for peptic ulcer (Orr, 1962; Kennedy et al., 1973; Amdrup et al., 1974). Most authors have reported bile vomiting in about $10 \%$ of patients studied after various surgical procedures (Capper and Welbourn, 1955; Dahlgren, 1964; Griffiths, 1974), but there is considerable variation between different series, probably because assessment is entirely subjective. After Billroth II partial gastrectomy, incidences between 1 and $26 \%$ have been reported (Nelson, 1968; McKeown, 1972).

Bile vomiting is often associated with the symptom of epigastric discomfort, which is thought to be due to duodenogastric reflux causing gastritis. Without an objective test for reflux, this concept has remained unproved. The selection of patients for bile diversion operations is based on the type and severity of symptoms but the evaluation of these criteria or the results of operation are similarly hampered by lack of objective measurement.

'Present address: Wycombe General Hospital, High Wycombe, Bucks.

${ }^{2}$ Address for reprint requests: Mr. J. Alexander-Williams, The General Hospital, Birmingham B4 6NH.

Received for publication 17 October 1977
Several methods of measuring duodenogastric reflux have been described. Assessment can be made radiologically (Capper et al., 1966) or endoscopically (Eckstam et al., 1974), but both methods are subjective and the presence of the duodenal tube or gastroscope may cause reflux. Aspiration from the stomach of a marker infused into the duodenum (Wormsley, 1972) is an objective method, but again a duodenal tube is needed. Bromsulphthalein and indocyanine green excreted in the bile may be measured in gastric aspirate and so avoid the need for a transpyloric tube (Faber et al., 1974). However, the concentration of bromsulphthalein in bile is not constant (Wirts and Cantarow, 1942), and the measurement of indocyanine green is difficult (Faber et al., 1974). Measurement of a naturally occurring duodenal 'marker' in gastric aspirates would be objective and would not itself induce reflux. Bilirubin is a natural 'marker', but is broken down by gastric acid and so its measurement gives unreliable results (Black et al., 1971). Similarly, trypsin is inactivated by acid (Khayat and Christophe, 1969). Sodium is a 'marker' that is simple to measure and stable (Faber et al., 1974), but it occurs in gastric as well as duodenal juice and 
so the calculations are difficult and further complicated by diffusion of sodium across the mucosal barrier, when it is damaged by bile (Ivey et al., 1970).

Bile acids are not normally found in the stomach and are not altered by intragastric acid. Rhodes et al. (1969) measured $\mathrm{C}^{14}$ labelled chenodeoxycholic acid in gastric aspirates and Black et al. (1971) measured bile acids enzymatically. Both authors found higher concentrations of bile acids in gastric aspirates from patients with gastric ulcer than from normal controls. Rhodes et al. (1969) demonstrated that the greatest difference between the two groups was achieved by examination of postprandial samples, but Black et al. (1971) found that fasting samples provided a better discriminant.

Measurement of bile acids in gastric aspirates has not been evaluated hitherto as a test for duodenogastric reflux after gastric surgery. We have conducted studies, first, to discover the best discriminant between patients with and without bile vomiting and dyspepsia and, second, to compare measurement of bile acids with endoscopy and radiology as a test of duodenogastric reflux.

\section{Methods}

BILE ACID ANALYSIS

Gastric aspirates were stored at $-20^{\circ} \mathrm{C}$ before analysis. Bile acids were extracted from the aspirate in methanol-acetone (Bruusgaard, 1970) and measured enzymatically by the method of Murphy et al. (1970) using pure 3 alpha-hydroxysteroid dehydrogenase (Fausa and Skålhegg, 1974).

The extraction efficiency was assessed using $C^{14}$-labelled sodium taurocholate and lithocholic acid, and by the addition of known amounts of sodium deoxycholate and sodium cholate to gastric aspirates. Ten experiments were performed in which the $\mathrm{pH}$ of the sample varied between 1.4 and 6.8 . 'Within day' precision was assessed by simultaneous extraction and analysis of 20 aliquots of the same specimen. 'Between day' precision was determined by extraction and analysis, with 20 batches of analysis, of one aliquot of pooled gastric aspirate. The limit of linearity and detection limit were also determined.

\section{TIMING OF SAMPLES FOR MEASUREMENT OF} BILE ACIDS

Fourteen patients, who had had a partial gastrectomy, volunteered for this study. Seven were asymptomatic and seven had symptoms typical of those ascribed to bile reflux (Bushkin et al., 1974). In each group there were six males and one female, of whom four had a vagotomy and antrectomy with Billroth I anastomosis and three Billroth II partial gastrectomy. The mean age of the asymptomatic group was 51.7 years and of the symptomatic group 35.6 years and duration since gastrectomy was 3.9 and 2.3 years respectively.

A size 14F Salem sump nasogastric tube was passed into the stomach of the fasting patient and its position checked fluoroscopically and by the water recovery test (Findlay et al., 1972). The gastric juice was aspirated and discarded and three 10-minute aspirates collected (fasting sample), then a pentagastrin test $(6 \mu \mathrm{g} / \mathrm{kg})$ was performed (pentagastrin sample). After a test meal ( $22 \mathrm{~g}$ corn oil and $56 \mathrm{~g}$ dextrose made up to $500 \mathrm{ml}$ with water) samples were aspirated at 30 and 60 minutes (postprandial sample). Gastric contents were then aspirated continuously from 10.00 p.m. to 7.00 a.m. (overnight sample). Before the tube was removed the next day fasting samples were repeated twice.

The concentration of bile salts in the three fasting samples was multiplied by the volume aspirated over half an hour and doubled; and termed 'fasting bile reflux' (FBR) expressed in $\mu \mathrm{mol} / \mathrm{hour}$.

\section{COMPARISON WITH REFLUX ASSESSED}

RADIOLOGICALLY AND ENDOSCOPICALLY

Radiological reflux was assessed using a modification of Capper's test (Keighley et al., 1975). Reflux was assessed as present or absent. Endoscopically, reflux was considered to be present if there was a pool of bile in the stomach or if reflux occurred throughout the examination.

Twenty asymptomatic patients were assessed by measurement of bile acids in the gastric aspirate and by radiology and endoscopy. Informed consent was obtained, and the study was approved by the hospital ethical committee. Details of these patients are given in the Table.

Fifteen symptomatic patients have been studied by all three methods and their age and previous operations are given in the Table. All had dyspepsia and vomiting and nine had bile regurgitation.

In 44 other patients, who had undergone a variety. of gastric operations, measurement of FBR was compared with aspirates obtained at endoscopy.

\section{Results}

BILE ACID ANALYSIS

The mean recovery of ( $\mathrm{C}^{14}$-carboxy-) sodium taurocholate and ( $\mathrm{C}^{14}$-carboxy-) lithocholic acid was $96.4 \%$ (range 93.2 to $100.2 \%$ ) and $93.4 \%$ (range 87.2 to $97.3 \%$ ) in experiments where the $\mathrm{pH}$ of the sample varied from 1.4 to $6 \cdot 8$. Recoveries of between 89.1 and $98.2 \%$ were obtained on addition of known amounts of pure sodium deoxycholate and sodium cholate to gastric aspirates. The mean bile acid concentration of the specimen used for 'within day' 
Table Age, sex and previous operations of patients in whom duodenogastric reflux has been assessed radiologically, endoscopically, and by measurement of $F B R$

\begin{tabular}{lll}
\hline & $\begin{array}{l}\text { Asymptomatic } \\
\text { patients }\end{array}$ & $\begin{array}{l}\text { Symptomatic } \\
\text { patients }\end{array}$ \\
\hline Number & 20 & 15 \\
Female & 3 & 4 \\
Mean age (yr) (and range) & $46 \cdot 7(25$ to 63) & $45 \cdot 2$ (21 to 64) \\
Previous operations & & \\
$\quad$ Proximal gastric vagotomy & 4 & 0 \\
Vagotomy and pyloroplasty & 1 & 4 \\
Vagotomy and antrectomy & 9 & 6 \\
Billroth II partial gastrectomy & 6 & 5 \\
\hline
\end{tabular}

precision was $856 \mu \mathrm{mol} / \mathrm{l}$, standard deviation 28.9 and coefficient of variation $3.4 \%$. Mean concentration of the sample used for between day variation was $1402 \mu \mathrm{mol} / 1$, standard deviation $144 \cdot 7$, and coefficient of variation $10.3 \%$.

\section{TIMING OF SAMPLES FOR MEASUREMENT OF} BILE ACIDS

The mean bile acid concentrations are shown in Fig. 1. There was no overlap of the mean of three 10 minute fasting samples, although one isolated fasting 10 minute sample from each of three symptomatic patients had low or absent bile acid concentrations. The amount of bile aspirated over 30 minutes when fasting (fasting bile reflux) separated those with symptoms from those without better than did the concentration of bile acids. FBR

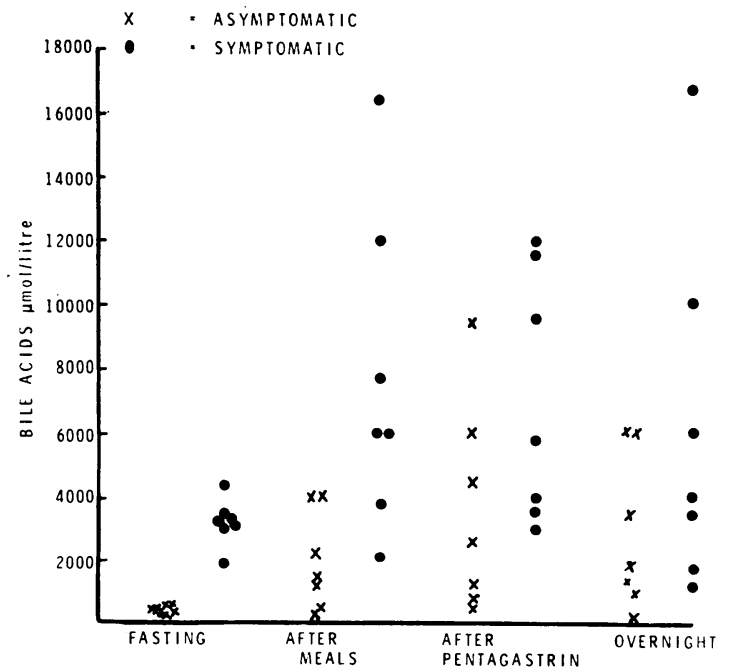

Fig. 1 Concentrations of bile acids in gastric aspirates obtained from the fasting patients, after food and pentagastrin and overnight. The mean of patients with and without symptoms are shown. measured on three occasions in each patient showed that the results are reproducible (Fig. 2). There was a significant correlation between samples obtained after food or pentagastrin using Spearman's rank correlation coefficient $(P<0.05)$.

\section{COMPARISON OF REFLUX BY FBR,} RADIOLOGY, AND ENDOSCOPY

In the 20 patients without symptoms, reflux was noted radiologically in five and endoscopically in 13. An FBR of less than $120 \mu \mathrm{mol} / \mathrm{h}$ was found in all asymptomatic patients.

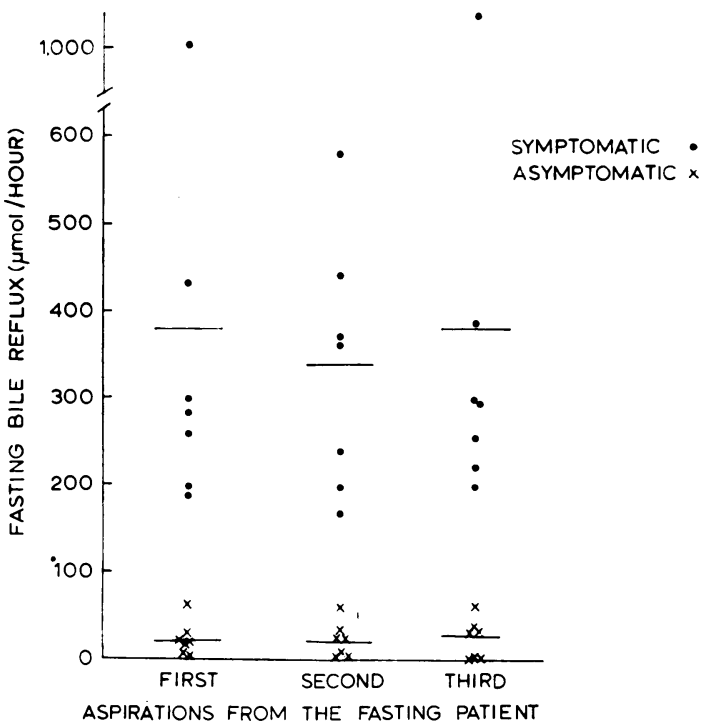

Fig. 2 Fasting bile reflux measured on three separate occasions in 14 patients is demonstrated.

Reflux was seen radiologically in 11 of the 15 patients with symptoms, endoscopically in 13 , and FBR was greater than $120 \mu \mathrm{mol} / \mathrm{h}$ in 10 . Nine of these 15 symptomatic patients complained of bile regurgitation and all nine had reflux seen during endoscopy and FBR greater than $120 \mu \mathrm{mol} / \mathrm{h}$, and eight had reflux demonstrated radiologically.

The concentration of bile acids in gastric aspirates obtained at endoscopy from 44 patients was compared with FBR measured via nasogastric tube in the same patients. High concentrations of bile acids in endoscopic aspirates did not necessarily indicate high FBR, but a concentration of less than 1000 $\mu \mathrm{mol} / \mathrm{l}$ was always associated with FBR of less than $100 \mu \mathrm{mol} / \mathrm{h}$.

\section{Discussion}

Measurement of bile acids in fasting gastric aspirates proved the best discriminant between patients with 
and without symptoms. FBR was less than $120 \mu \mathrm{mol} / \mathrm{h}$ in all of 20 asymptomatic patients, and over $120 \mu \mathrm{mol} / \mathrm{h}$ in $77 \%$ of a total of 22 symptomatic patients and in all of the 16 with symptoms of bile regurgitation.

The method of estimating FBR is simple. The basal collection before a pentagastrin test can be used as the sample for measurement of FBR. The technique using methanol acetone is easy and extraction was as complete as that obtained with the more complicated method of Murphy et al. (1970). Acid studies are usually performed in trials comparing different gastric operations, and this objective test of bile reflux could be included without any further discomfort to the patient.

Both radiology and endoscopy demonstrated duodenogastric reflux in some of the 20 patients studied who had no symptoms after gastric surgery. FBR was less than $120 \mu \mathrm{mol} / \mathrm{h}$ in all these patients, and is therefore more reliable than radiological or endoscopic assessments of reflux. Gastroscopy is, of course, necessary to exclude the presence of a recurrent ulcer in most of these patients, and if sampling of gastric juice can be used as a screening test to exclude significant bile reflux. FBR can measure bile reflux, and so determine if that reflux is likely to be the cause of symptoms, and a separate study (Hoare et al., 1978) has shown that it can predict who will benefit from bile-diversion operations.

\section{References}

Amdrup, E., Jensen, H. E., Johnston, D., Walker, B. E., and Goligher, J. C. (1974). Clinical results of parietal cell vagotomy (highly selective vagotomy) two to four years after operation. Annals of Surgery, 180, 279-284.

Black, R. B., Roberts, G., and Rhodes, J. (1971). The effect of healing on bile reflux in gastric ulcer. Gut, 12, 552-558.

Bruusgaard, A. (1970). Quantitative determination of the major 3-hydroxy bile acids in biological material after thin-layer chromatographic separation. Clinica Chimica Acta, 28, 495-504.

Bushkin, F. L., Wickbom, G., De Ford, J. W., and Woodward, E. R. (1974). Postoperative alkaline reflux gastritis. Surgery, Gynecology and Obstetrics, 138, 933-939.

Capper, W. M., Airth, G. R., and Kilby, J. O. (1966). A test for pyloric regurgitation. Lancet, 2, 621-623.

Capper, W. M., and Welbourn, R. B. (1955). Early postcibal symptoms following gastrectomy. Aetiological factors, treatment and prevention. British Journal of Surgery, 43, 24-35.

Dahlgren, S. (1964). The afferent loop syndrome. Acta Chirurgica Scandinavica, suppl., 327, 1-149.

Eckstam, E. E., Scudamore, H. H., Fencil, W. J., and Jaramillo, C. A. (1974). Bile reflux gastritis. Results of surgical therapy with Roux-en-Y gastrojejunostomy. Wisconsin Medical Journal, 73, s75-s78.

Faber, R. G., Russell, R. C. G., Royston, C. M. S., Whitfield, P., and Hobsley, M. (1974). Duodenal reflux during insulin-stimulated secretion. Gut, 15, 880-884.

Fausa, O., and Skålhegg, B. A. (1974). Quantitative determination of bile acids and their conjugates using thin-layer chromatography and a purified 3 alpha hydroxysteroid dehydrogenase. Scandinavian Journal of Gastroenterology, 9, 249-254.

Fiddian-Green, R. G., Whitfield, P., Russell, R. C. G., Faber, R. G., and Hobsley, M. (1974). Indocyanine green as a marker of duodenal reflux in aspirated gastric juice (abstract). British Journal of Surgery, 61, 323-324.

Findlay, J. M., Prescott, R. J., and Sircus, W. (1972). Comparative evaluation of water recovery test and fluoroscopic screening in positioning a nasogastric tube during gastric secretory studies. British Medical Journal, 4, 458-461.

Griffiths, J. M. T. (1964). The features and course of bile vomiting following gastric surgery. British Journal of Surgery, 61, 617-622.

Hoare, A. M., McLeish, A., Thompson, H., and AlexanderWilliams, J. (1978). Selection of patients for bile division surgery: use of bile acid measurements in fasting gastric aspirates. Gut, 19, 163-165.

Ivey, K. J., DenBesten, L., and Clifton, J. A. (1970). Effect of bile salts on ionic movement across the human gastric mucosa. Gastroenterology, 59, 683-690.

Keighley, M. R. B., Asquith, P., and Alexander-Williams, J. (1975). Duodenogastric reflux: a cause of gastric mucosal hyperaemia and symptoms after operations for peptic ulceration, Gut, 16, 28-32.

Kennedy, T., Connell, A. M., Love, A. H. G., Macrae, K. D., and Spencer, E. F. A. (1973). Selective or truncal vagotomy? Five year results of a double-blind, randomized, controlled trial. British Journal of Surgery, 60, 944-948.

Khayat, M. H., and Christophe, J. (1969). In vitro inactivation of pancreatic enzymes in washings of the rat small intestine. American Journal of Physiology, 217, 923-929.

McKeown, K. C. (1972). A prospective study of the immediate long-term results of polya gastrectomy for duodenal ulcer. British Journal of Surgery, 59, 849-868.

Murphy, G. M., Billing, B. H., and Baron, D. N. (1970). A fluorimetric and enzymatic method for the estimation of serum total bile acids. Journal of Clinical Pathology, 23, 594-598.

Nelson, P. G. (1968). Early post-cibal symptoms after surgery for duodenal ulcer. Australia and New Zealand Journal of Surgery, 37, 283-288.

Orr, I. M. (1962). Selective surgery for peptic ulcer. Followup studies on a series of 1502 operations for peptic ulcer carried out by the selective policy. British Journal of Surgery, 50, 121-130.

Rhodes, J., Barnardo, D. E., Philips, S. F., Rovelstad, R. A., and Hofmann, A. F. (1969). Increased reflux of bile into the stomach in patients with gastric ulcer. Gastroenterology, 57, 241-252.

Wirts, C. W., and Cantarow, A. (1942). A study of the excretion of bromsulphthalein in the bile. American Journal of Digestive Diseases, 9, 101-106.

Wormsley, K. G. (1972). Aspects of duodeno-gastric reflux in man. Gut, 13, 243-250. 